\title{
THE IMPACT OF ICTS ON CORE SECTORS OF THE NIGERIAN ECONOMY
}

\author{
George N. Ike, Dike U. Ike \\ Department of Economics, Covenant University, Nigeria. \\ Department of Electrical and Information Engineering, Covenant University, Nigeria.
}

\begin{abstract}
Information and Communication Technology (ICT) has taken the center stage in almost every aspect of human endeavor. ICT help companies to improve the efficiency and effectiveness of services offered to customers, and thus enhances business processes, managerial decision making, and workgroup collaborations, thus strengthening their competitive positions in rapidly changing and emerging economies. This paper considers the impacts and trends of ICTs on core sectors of the Nigerian economy. Three core industry sectors of the Nigerian economy were examined namely: Banking Industry, Oil and Gas Industry, and Agricultural Industry in order to examine the level of impact ICTs have on the overall Nigerian economy.
\end{abstract}

\section{Key words:}

Agricultural Industry, Banking Industry, ICT, Nigerian economy, Oil and Gas Industry

\section{Academic Discipline:}

Economics, Information Technology

\section{Council for Innovative Research}

Peer Review Research Publishing System

\section{Journal of Social Science Research}

Vol.1, No.3

editor@jssronline.com

www.cirworld.com, www.jssronline.com 


\subsection{Introduction}

The Nigerian economy is currently supported by oil, which is the major non-renewable energy source. ICTs play an important role in increasing productivity and efficiency in many sectors of the economy. Industries particularly adopt ICTs to improve the efficiency and effectiveness of their operations, as well as to aid management decision making. This helps to strenghten their competitive positions in rapidly changing environments. Environmental, organizational, and technological factors are creating a highly competitive business environment in which customers are the focal point [1]. Furthermore, these factors can change very quickly. Thus, the growth of any company is tied to retaining loyal customers, improving productivity, reducing costs, increasing market share, and providing timely organizational response [2]. ICT is a major tool for dealing with these issues. Due to the degree of uncertainty in todays economy, companies in Nigeria are operating under increasing pressures to produce more with minimum resources. In order to succeed in this dynamic environment, companies must undertake innovative activities such as improving operational processes and continuously reviewing competitive strategies. This paper examines the impact of ICT on core sectors of the Nigerian economy.

\subsection{Overview of Information and Communication Technology}

Information and Communication Technologies (ICTs) are devices used to communicate between computers. ICTs have taken over nearly every aspect of our daily lives from commerce to leisure and even culture. Today, computers, laptops, tablets, and the use of Internet has become a core part of our culture and society. These technologies play a vital role in our day to day operations.

ICT has made global socio-cultural integration very easy. We now live in an interdependent global society, where individuals can interact and communicate quickly and efficiently. News and information can now be transmitted quickly all over the world. Some of the advantages of new ICT technology include; Faster processing of data, faster availability of data, greater storage and security of data and so on.

\subsection{Nigeria Industry Sectors}

Till 1956, Nigeria's industry sectors were dominated by agricultural production. The country's fertile land and abundant mineral resources fueled the economy. However, the 1970 s oil boom changed the entire equation. The oil sector became the mainstay of the economy. As foreign currency began to pour in through the oil sector, the government neglected the agriculture and non-oil industrial sectors. Massive migration from villages to oil-producing cities resulted in large unemployment and low standard of living. The mining sector, including the oil and natural gas segment, is the largest Nigeria industry sector. According to the 2005 figures, it accounts for more than $90 \%$ of the annual national production and generates more than $80 \%$ of the government revenues. The country produces 2.169 
million barrels per day (2007 statistics). In terms of oil export volumes, the country ranks 8 th in the world. The Nigerian oil sector is regulated by the Nigerian National Oil Corporation (NNOC). It is a member country of the Organization of Petroleum Exporting Countries (OPEC). Although major reforms have been undertaken to liberalize the country's economy, the oil sector is still under the close scrutiny of the government[3].

Other major industrial sectors in Nigeria are:

Telecommunication: In the economic reforms of 2005, the government laid huge emphasis on improving the telecommunication sector. The Nigeria Communications Commission has the responsibility to develop mobile and internet communication facilities in the country.

Banking: The government has laid huge emphasis on improving the banking sector. The Central Bank of Nigeria has the responsibility to develop and execute the banking sector reforms.

\subsection{Impact of ICTs in Banks}

Nigerian banking Industry has been undergoing major changes, reflecting a number of underlying developments. Advancement in communication and information technology has facilitated growth in internet-banking, ATM Network, Electronic transfer of funds and quick dissemination of information. Structural reforms in the banking sector have improved the health of the banking sector. The reforms recently introduced include the enactment of the Securitization Act to step up loan recoveries [4], establishment of asset reconstruction companies, initiatives on improving recoveries from Non-performing Assets (NPAs) and change in the basis of income recognition has raised transparency and efficiency in the banking system. Increase in treasury income and improvement in loan recoveries has helped Nigerian Banks to record better profitability. Reforms have compelled banks to improve the utilization of ICT. The recently introduced handling charge on cash based transaction by the CBN is a pointer to the ever increasing role of ICT in the Nigerian banking industry. The level of information and communication technology used in a company depends significantly on variables such as the scale and type of activity. The actual ICT tools used in a company would depend on the company operation. ICT has productivity increasing effects on labor productivity and total factor productivity of industries. ICT-induced productivity effects vary significantly between sectors and among countries. The banking industry is one of the sectors that enjoy the largest productivity growth effect of ICT.

The use of computers and peripherals simplifies the task of getting customers' data and counting money to effect transaction. This enables a single cashier to serve thousands of customers in a day which would have cost the bank enormous staff strength and large building. Nigerian banks need to multiplex ICT investments with complementary investment in working practices, human capital, and firm restructuring to optimize its impact on productivity. Technological change forces firms to adopt new modes of production and, consequently, to reorganize its assets. If a company fails to reorganize internally, it will probably disappear from the industry and its assets will be reorganized externally. New technology spreads faster if such asset reallocation works smoothly [5]. The diffusion of ICT is technological change that has greatly revolutionized the banking sector.

Empirical findings suggest that some of the main effects of ICT diffusion are organizational changes and the redefining of organizational boundaries [5]. Thus, it is relevant to assess if the diffusion of ICT in the banking industry had any impact on the restructuring process. The impact on value chain reflects in re-shaping firm boundaries and changing the constellations of value chains are enormous. The number of branches a bank has is another value chain that enhances the impact and level of deployment of ICT.

\subsection{Impact of ICT in the Oil and Gas Industry}

In Nigeria, oil and gas operations commenced with the first commercially viable discovery at Oloibiri in the Niger Delta in 1956 by the then Shell D'Arcy. Shell continued to play a dominant role, until Nigeria's membership of the Organization of Petroleum Exporting Countries (OPEC) in 1971, subsequently, Nigeria began to take a firmer control of its oil and gas resources, in line with the practice of other OPEC countries. National Oil Companies (NOCs) were 
set-up across OPEC member countries, with the sole responsibility of monitoring the stake of the oil-producing countries in the exploitation of the oil resource. The NOC's took direct control of oil production operations in some OPEC member countries, but in Nigeria, the Multinational Oil Companies (MNOCs) were allowed to continue with oil production operations under the Joint Operating Agreement (JOA) which specifies the respective stakes of the companies and the Federal Government of Nigeria in the ventures. The multinational oil companies operate in partnership with NNPC under Joint Operating Agreements (JOAs) or Production Sharing Contracts (PSCs).

Other MNOCs came on the scene during this period, such as Gulf oil and Texaco (now Chevron), Elf Petroleum (now Total), Mobil (now Exxon Mobil), and Agip, in addition to Shell, which was already playing a dominant role in the industry. These other companies were also operating JOAs with NNPC, with varying percentages of stakes in their respective acreages. To date, the above companies constitute the major players in the industry, accounting for most of the total oil and gas production in Nigeria today [6]. The use of ICTs in the oil and gas industry in Nigeria is not only useful to the International Oil Companies (IOCs) in their quest to remain technologically relevant, but it is also useful to the National Oil Companies in Nigeria and other OPEC countries.

Advances in science has led to an increase in the role of automation, computation and other analytical techniques, and has thus led to an increase in the use of ICTs in the oil and gas industry. ICTs can increase efficiency in the oil and gas industry, through modern software solutions for complex multiple input systems. In the oil and gas industry, ICT use vary from simple solutions such as e-mail, and internet, to the use of more advanced solutions such as advanced digital data networks or sensor devices measuring the oil extraction operation. It is estimated that major oil companies, including Chevron, Exxon-Mobil, Shell, Agip, and Total, spend over ten billion dollars a year on ICTs in all their oil and gas operations worldwide.

In order for ICT solutions to be fully realised, there should be sufficient capital to invest in modern technologies, and adequate skilled manpower to be able to apply and work with the new technology. Employees need to be able to easily interpret data from control systems, and derive useful knowledge from such data and take quick collective decisions on the optimization of business processes. ICTs can contribute to the extension of oil reserves beyond existing levels, and increase the rate of crude oil extraction from existing oil wells. Figure 1 below summarizes the use of ICTs in the oil and gas industry.

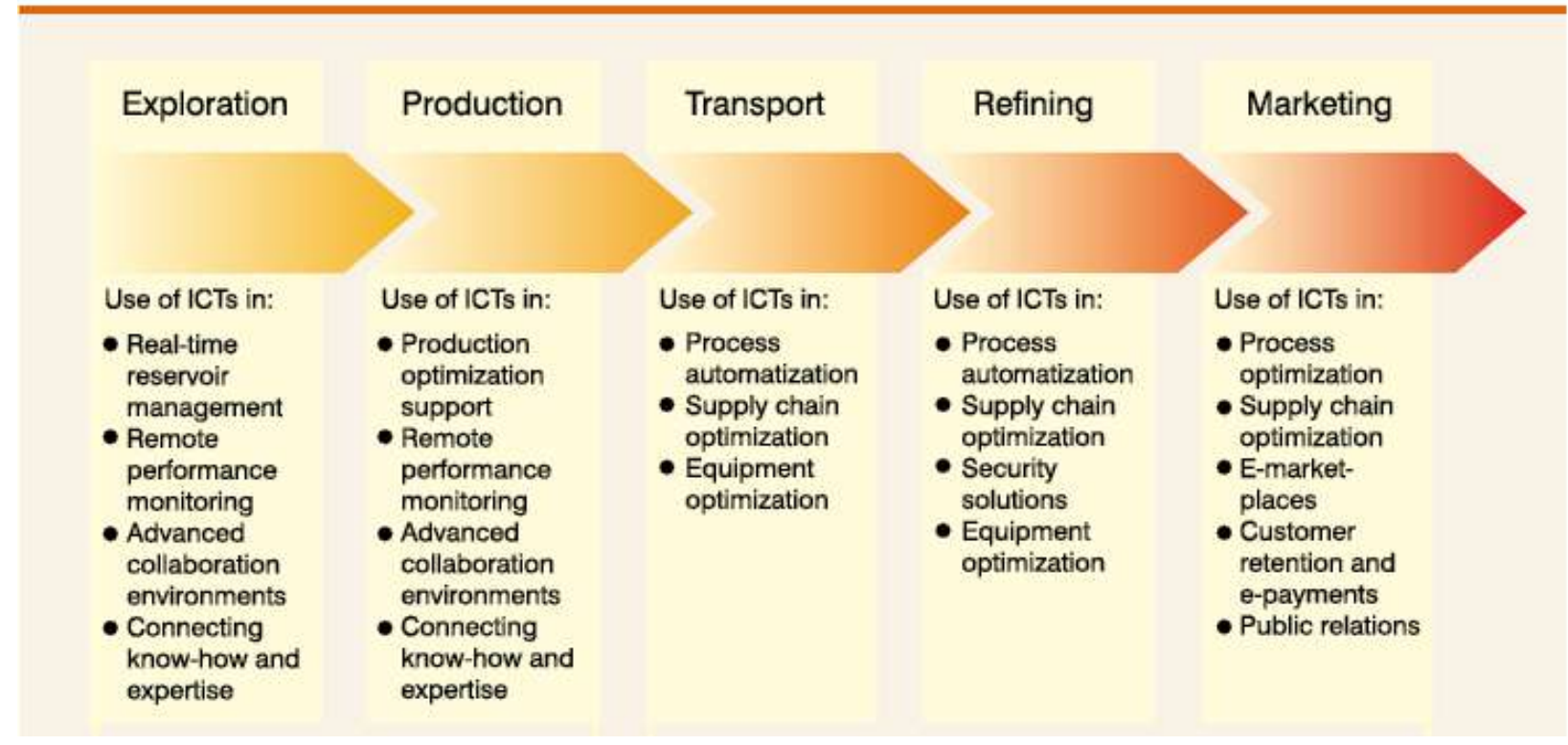

Figure 1: ICTs use in the Oil and Gas Industry[7] 


\subsection{Impact of ICTs in the Agricultural Sector}

Agriculture in Nigeria is a major branch of the economy in Nigeria, providing employment for $70 \%$ of the population. The sector is being transformed by commercialization at the small, medium and large-scale enterprise levels [8]. Some of the areas of ICT application in Agriculture include;

I. Global Positioning System - In agriculture, the use of the Global Positioning System provides benefits in geofencing, map-making and surveying. With the use of GPS, Nigerian farmers can produce highly accurate digitized map of a farm.

II. Geographic Information Systems - Geographic information systems, or GIS, are extensively used in agriculture, especially in precision farming. Land is mapped digitally, and pertinent geodetic data such as topography and contours are combined with other statistical data for easier analysis of the soil. GIS is used in decision making such as what to plant and where to plant using historical data and sampling.

III. Computer Controlled Devices - Automatic milking systems are computer controlled stand alone systems that milk the dairy cattle without human labor. The complete automation of the milking process is controlled by an agricultural robot,a complex herd management software, and specialized computers. Automatic milking eliminates the farmer from the actual milking process, allowing for more time for supervision of the farm and the herd. Farmers can also improve herd management by using the data gathered by the computer. By analyzing the effect of various animal feeds on milk yield, farmers may adjust accordingly to obtain optimal milk yields. Since the data is available down to individual level, each cow may be tracked and examined, and the farmer may be alerted when there are unusual changes that could mean sickness or injuries [9].

IV. RFID - The Veterinary Department of Nigeria's Ministry of Agriculture can introduce a livestock-tracking program to track the estimated 80,000 cattles all across the country. Each cattle will be tagged with the use of RFID technology for easier identification, providing access to relevant data such as: bearer's location, name of breeder, origin of livestock, sex, and dates of movement [10].

\subsection{Conclusion}

Investment on ICT infrastructures has become a key element in productivity and growth in various sectors of the Nigerian economy. Increased investment in ICT-Capital has accelerated growth in core industries. Also, ICT facilitates the absorption of high and medium skilled labor. This has a positive effect on the labor output of industries. However, ICT investment does not lead to industrial growth by itself, It depends on how the technology is actually used in business processes, i.e. on an organization's ability to innovate its work processes and business routines with the use of ICT. Thus, ICT use has to be combined with excellent working practices, human and material capital, and organizational structure for it to have an impact on performance.

\section{References}

[1] Efraim Turban, Dorothy Leidner, Ephraim McLean, James Wetherbe, "Information Technology for Management: Transforming Organizations in the Digital Economy", 3rd edit., John Wiley \& Sons, Inc., pp.10-15. ISBN 978-0-47178712-9.

[2] Matthew K. Luka, Ibikunle A. Frank, "Impact of ICTs on Banks: A Case Study of the Nigerian Banking Industry", International Journal of Advanced Computer Science and Applications, Vol.3, No.9, 2012.

[3] Economy Watch, "Nigeria Industry Sectors", retrieved on June 20, 2013, from http://www.economywatch.com/world_economy/nigeria/industry-sector-industries.html.

[4] The Senate Federal Republic Of Nigeria, "A Bill For An Act To Establish The Asset Management Corporation Of Nigeria For The Purpose Of efficiently Resolving The Non-Performing Loan Assets Of Banks In Nigeria And For Related Matters", Asset Management Corporation Of Nigeria Bill, 2010. Retrived on March 20th, 2012 from: http://www.proshareng.com/admin/upload/reports/2705.pdf 
[5] Brynjolfsson E., Malone T. W., Gurbaxani V., and Kambil A. "Does Information Technology Lead to Smaller Firms?", Management Science, Vol. 40, No. 12, pp. 1628-1644, 1994.

[6] http://www.pengassan.org

[7] UNCTAD (2006). ICTS In The Oil Sector: Implications For Developing Economies. Chapter 4, Information Economy Report 2006.

[8] Olomola Ade S. (2007) "Strategies for Managing the Opportunities and Challenges of the Current Agricultural Commodity Booms in SSA" in Seminar Papers on Managing Commodity Booms in Sub-Saharan Africa: A Publication of the AERC Senior Policy Seminar IX. African Economic Research Consortium (AERC), Nairobi, Kenya.

[9]"EU-Project Automatic milking". Wageningen UR. 20 February 2008. Retrieved 15 March 2013.

[10] "Malaysia begins RFID-enabled livestock tracking program". RFIDNews. 6 April 2009. Retrieved 15 March 2013

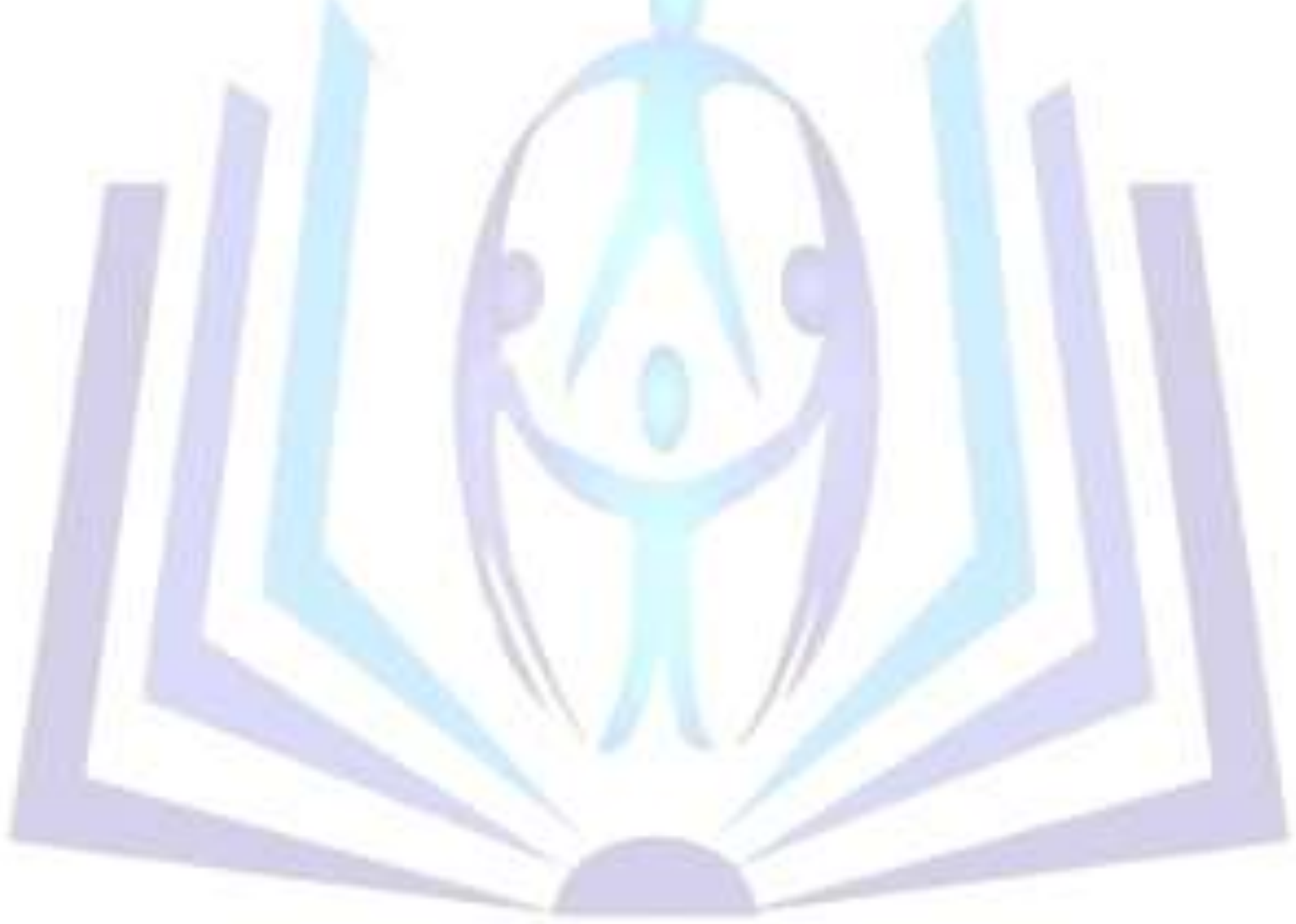

